\section{In-patient psychotherapy}

SIR: We were interested to read Norton \& Hinshelwood's (1996) account of the clinical need for in-patient psychotherapy units. However, we do not believe that in-patient psychotherapy units are the only, or indeed the best treatment for these patients. In-patient units are expensive to run, make heavy demands on staff round the clock, and remove patients from their normal environment and support networks.

We run a therapeutic community as a day service, which is open for five days a week and caters for a similar patient population at a district level. Like the Henderson, the programme is one of milieu therapy with intensive group psychotherapy. There is no individual treatment. Like the Cassel, the analytic principles of "a culture of enquiry" and staffing and supervision to prevent splitting and other destructive defensive procedures are paramount.

The advantages of having day patient treatment are financial, administrative and clinical. Treatment costs are approximately half of in-patient facilities, and the complexities of staffing the unit are much less. A considerable clinical advantage is the on-call system for out of hours run by the patients themselves, which is seen as an important part of the therapeutic process itself. For many patients it is also important that their previous social functioning continues during their admission, and this is particularly important for those who are parents.

Norton, K. \& Hinshel wood, R. D. (1996) Severe personality disorder. Treatment issues and selection for in-patient psychotherapy. British Journal of Psychiatry, 168, 723-731.

R. HAIGH

West Berkshire Psychotherapy Service 53-55 Argyle House

Reading RG1 $7 Y L$

\section{Antipsychotic drug-induced dysphoria}

SIR: Gray et al (1996) cite four flaws in King et al s (1995) report which in their view invalidate their conclusions. We wish to report observations made in a further healthy volunteer study which are relevant to their concerns.

In a study designed to assess the cognitive and psychomotor effects of haloperidol, 15 male volunteers aged 18-26 years were given single doses of haloperidol 2,4 and $6 \mathrm{mg}$, lorazepam $2.5 \mathrm{mg}$ and placebo at weekly intervals in a double-blind, repeated measures design. When given $6 \mathrm{mg}$ of haloperidol, 12 volunteers experienced adverse effects, variously described by them as restlessness, irritability or tension. Three volunteers described the effects as 'severe' or 'very severe', six as 'moderate' and three as 'mild'. In most of these cases the effects began between 3 and 5 hours after drug administration, but two subjects developed symptoms at 6 and 8 hours respectively. Symptoms were treated with procyclidine $5 \mathrm{mg}$ in nine volunteers, which gave relief to the symptoms. Two volunteers who did not receive procyclidine had persistent symptoms resulting in insomnia that night, and lasting more than 24 hours.

At the $4 \mathrm{mg}$ dose of haloperidol, nine volunteers experienced similar adverse effects, two rating the effects as 'severe' or 'very severe', one as 'moderate' and six as 'mild'. Once again, two volunteers experienced late onset of symptoms at $6-8$ hours but most described the onset of symptoms at 3-4 hours. One volunteer described mild restlessness three hours after receiving the $2 \mathrm{mg}$ dose. Thus, dysphoria occurred in $80 \%$ of subjects receiving $6 \mathrm{mg}$ of haloperidol, $60 \%$ receiving $4 \mathrm{mg}$ of haloperidol and $6 \%$ receiving $2 \mathrm{mg}$ of haloperidol. Dysphoria occurred in the absence of objective signs of akathisia. In most cases the onset of symptoms coincided with the theoretical time of peak plasma levels, but in a significant minority of cases the effects are delayed. These studies were not designed specifically to examine adverse effects of antipsychotic drugs, and we agree with Gray et al that the area of antipsychotic drug-induced dysphoria requires further rigorous investigation.

Gray, R., Brown, C., Hooghamer, R., et al (1996) Antipsychotic drug-induced dysphoria. British Journal of Psychiatry, 168, 655-656.

KNG, D. J., Burke, M. \& LuCAs, R. A. (1995) Antipsychotic drug-induced dysphoria. British Journal of Psychiatry, 167, $480-482$.

Holywell Hospital

G. LYNCH

Steeple Road

Antrim

J. F. GrereN

The Queen's University of Belfast

D. J. KING

Belfast BT9 7BL

Inappropriate secretion of antidiuretic hormone and SSRIs

SR: We have observed hyponatraemia in an elderly depressive patient treated with the SSRI citalopram. The SIADH syndrome has been described 
for other SSRIs such as fluoxetine (Hwang \& Magraw, 1989), sertraline (Thornton \& Resch, 1995) and paroxetine (Lisi, 1993), but not for citalopram.

\section{Case report}

Mrs. A, a 73-year-old woman suffering from a bipolar affective disorder and from hypertension was medicated with diuretics (hydrochlorothiazide and amiloride) resulting in several episodes of hyponatraemia. The first episode occurred seven years before present hospitalisation, with a $\mathrm{Na}$ concentration of $126 \mathrm{mmol} / \mathrm{l}$ (normal range: 137$150 \mathrm{mmol} / \mathrm{l}$ ). After one month of severe depression, the patient was hospitalised due to non-response to amitriptyline and penfluridol. She was depressed, retarded, confused, and complained of extreme fatigue. $\mathrm{Na}$ and $\mathrm{K}$ serum concentrations were low: $121 \mathrm{mmol} / \mathrm{h}$ and $3.21 \mathrm{mmol} / \mathrm{l}(3.5-5.3 \mathrm{mmo} / /)$, respectively. Medication with amitriptyline was discontinued, but it was only after stopping administration of hydrochlorothiazide and amiloride, and after installing hydrous restriction and providing a supplement of electrolytes that serum $\mathrm{Na}$ and $\mathrm{K}$ normalised.

One month later, we introduced citalopram (20 mg/day). Serum $\mathrm{Na}$ decreased to $133 \mathrm{mmol} / \mathrm{l}$ and then to $128 \mathrm{mmol}$, after 7 and 10 days of treatment, respectively, while serum $K$ and urea remained within the normal range. The patient equally became more anxious and retarded. Citalopram treatment was then interrupted, $6 \mathrm{~g}$ of $\mathrm{NaCl}$ was administered for 3 days, and a hydrous restriction was installed. Within one month, serum $\mathrm{Na}$ slowly normalised ( 3 days after discontinuation of citalopram: $131 \mathrm{mmol} / /$; 4 days: $133 \mathrm{mmol} / / 24$ days: $138 \mathrm{mmol} / \mathrm{l})$. Four days after discontinuation of citalopram treatment, blood osmolality was decreased to $264 \mathrm{mmol} / \mathrm{kg} \quad(270-295 \mathrm{mmol} / \mathrm{kg})$, while urinary osmolality was $522 \mathrm{mmol} / \mathrm{kg}$ ( 50 $1400 \mathrm{mmol} / \mathrm{kg}$ ). These values, the normalisation of serum $\mathrm{Na}$ after discontinuation of citalopram, and the absence of any other treatment suggest the involvement of citalopram in this hyponatraemia. Moreover, it did not reappear after a later treatment with maprotiline and flupenthixol.

Diuretics and fluoxetine represent a risk factor of developing hyponatraemia, but apparently not age (Siegler et al, 1995). While no report has yet been published about hyponatraemia after citalopram administration, Mrs A first developed it after administration of diuretics. For unknown reasons, this person may belong to that part of the popula- tion who run a risk of developing hyponatraemia, and which reappeared after treatment with citalopram. Therefore, in patients who have already developed hyponatraemia while being medicated with diuretics, serum electrolytes should be carefully monitored when comedicated with SSRIs.

Hwang, A. S. \& Magraw, R. M. (1989) Syndrome of inappropriate secretion of antidiuretic hormone due to fluoxetine. American Journal of Psychiatry, 146, 399.

LISI, D. M. (1993) Comment: paroxetine-associated hyponatremia. Annals of Pharmacotherapy, 27, 1547-1548.

Stegler, E. L., TAMres, D., BerLn, J. A., et al (1995) Risk factors for the development of hyponatremia in psychiatric inpatients. Archives of Internal Medicine, 155, 953-957.

ThORNTON, S. L. \& Resch, D. S. (1995) SIADH associated with sertraline therapy. American Journal of Psychiatry, 152, 809.

Service Universitaire de Psychogériatrie

J. VOEGELI CH-1008 Prilly-Lausanne, Switzerland

P. BaUmanN
Département Universitaire de Psychiatrie Adulte
CH-1008 Prilly-Lausanne, Switzerland

\section{Seizure length during ECT}

SIR: Seizure activity is important to therapeutic success during electroconvulsive therapy (ECT) and Scott \& Lock (1995) have recommended that peripheral seizures should be at least 15 seconds (maximum 90 seconds). A number of SSRIs have been reported to increase seizure length during ECT including fluoxetine (Gutierrez-Esteinou \& Pope, 1989) and paroxetine (Curran, 1995). In addition, the Special Committee on ECT of the Royal College of Psychiatrists has received a number of reports of increased seizure length in patients taking SSRIs but there have been no reports concerning fluvoxamine (Curran \& Freeman, 1995).

A patient recently under the care of the authors with DSM-IV major depression underwent a course of ECT. Physical examination and routine investigations were all normal. The only medication taken by the patient was fluvoxamine $100 \mathrm{mg}$ bd. Seizure length was determined in accordance with Royal College of Psychiatrists guidelines and the patient received a course of six treatments. The average seizure length during treatment was 63.1 seconds (s.d. 28.0, range 26-111). This average seizure duration was approximately double that observed in the same ECT department over the same period; the highest previous seizure length recorded in our department was 75 seconds. In addition, the correlation between seizure length and stimulus dose in $\mathrm{mC}$ was low (Spearman Rank 